Оригинальная статья/Original article

\begin{tabular}{l}
\hline УДК 637 \\
\hline DOI: http://doi.org/10.20914/2310-1202-2016-2-148-152
\end{tabular}

Кисломолочный продукт функционального назначения

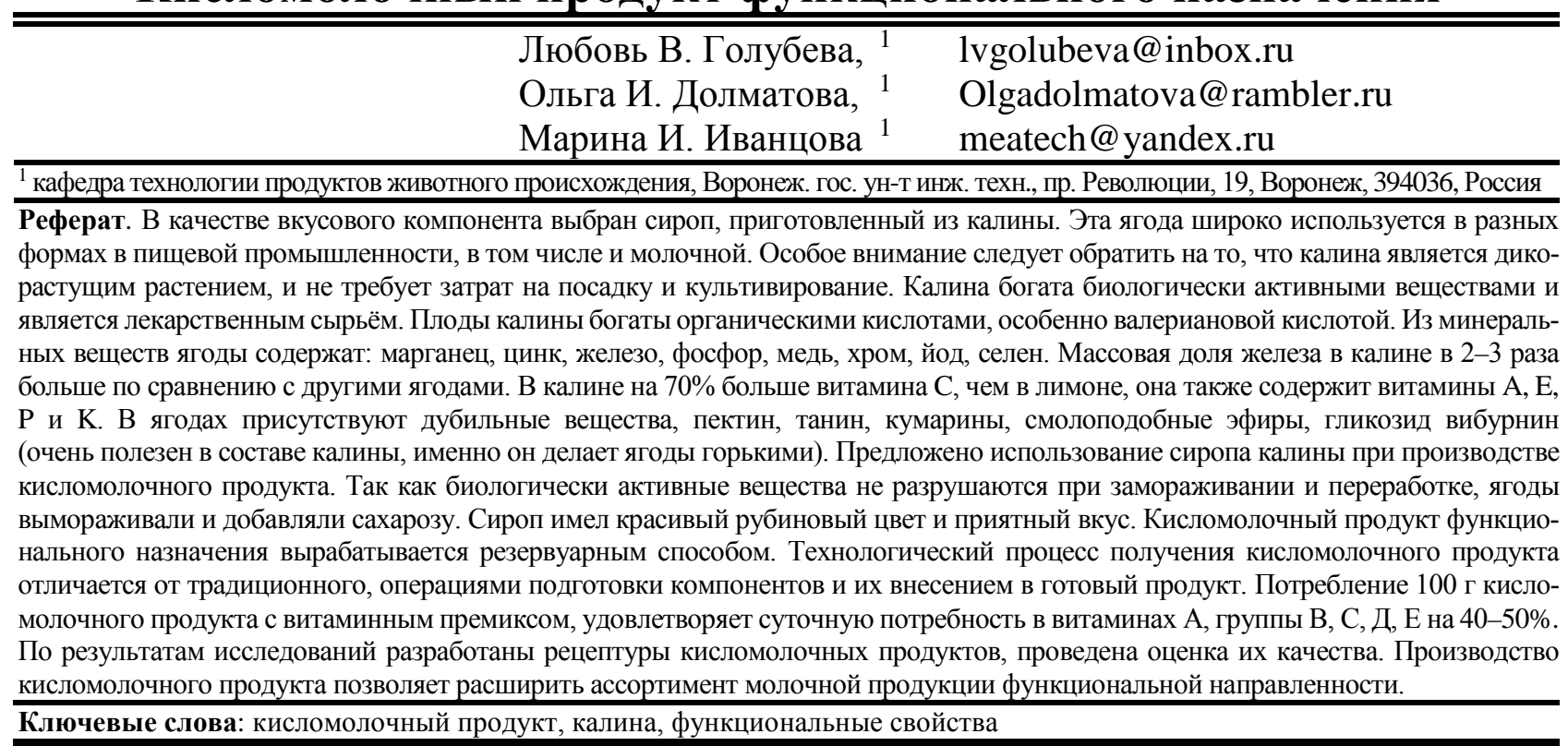

\title{
The fermented milk product of functional destination
}

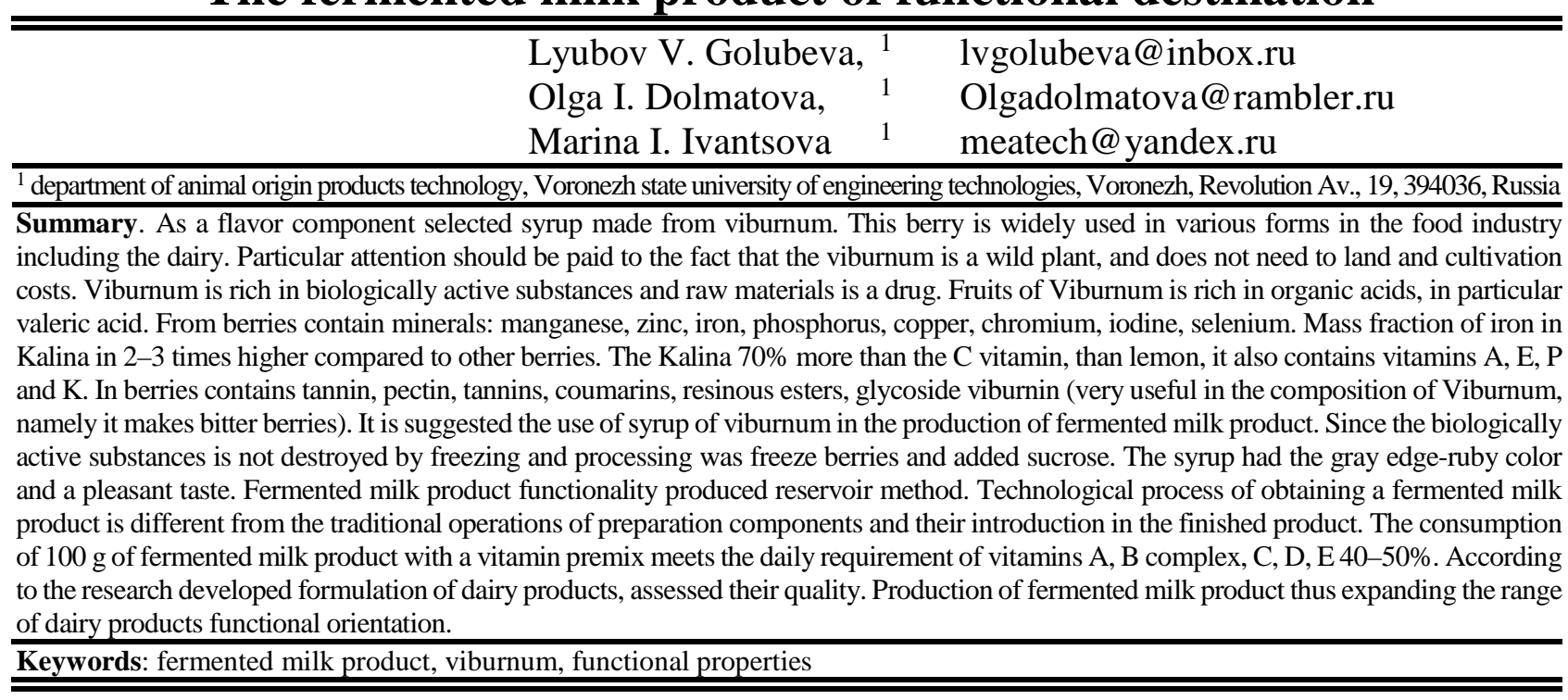

\section{Введение}

Индустрия питания за последнее десятилетие существенно изменилась. Если раньше были широко востребованы калорийные продукты, то сегодня популярны здоровые, со сбалансированным составом, в том числе функциональные.

Согласно ТР ТС «O безопасности молока и молочных продуктов» функциональным является специальный пищевой продукт, предназначенный для систематического употребления

Для цитирования

Голубева Л. В., Долматова О. И., Иванцова М. И. Кисломолочный продукт функционального назначения // Вестник ВГУИТ. 2016. № 2. С. 148-152. doi:10.20914/2310-1202-2016-2-148-152 148 в составе рационов всеми возрастными группами здорового населения и характеризующийся научно обоснованными и подтверждёнными свойствами, снижающий риск развития заболеваний, связанных с питанием, предотвращающий дефицит или восполняющий имеющийся в организме человека дефицит питательных веществ, сохраняющий и улучшающий здоровье за счёт наличия в его составе физиологически функциональных ингредиентов.

For citation

Golubeva L. V., Dolmatova O. I., Ivantsova M. I. The fermented milk product of functional destination. Vestnik VSUET [Proceedings of VSUET]. 2016. no. 2. pp. 148-152 (in Russ.). doi:10.20914/2310-1202-2016-2-148-152 
Кисломолочные продукты обладают рядом полезных свойств: способствуют нормализации деятельности желудочно-кишечного тракта, по сравнению с молоком они легче и быстрее усваиваются организмом человека и др. [1]. Это связано с тем, что в них при сквашивании происходят изменения, в т. ч частичный протеолиз белков. Кисломолочные продукты широко востребованы на российском рынке, поэтому разработка технологии кисломолочного продукта функционального назначения актуальна.

\section{1 Материалы и методы}

В качестве вкусового компонента выбран сироп, приготовленный из калины. Эта ягода широко используется в разных формах в пищевой промышленности, в том числе и молочной.

Особое внимание следует обратить на то, что калина является дикорастущим растением, и не требует затрат на посадку и культивирование. Калина богата биологически активными веществами и является лекарственным сырьём.

Антиоксидантная активность сиропа калины определена на приборе Цвет Яуза-01-АА.

Основные органолептические, физикохимические показатели кисломолочного продукта определяли стандартными и общепринятыми в молочной промышленности методами.

\section{2 Результаты и обсуждение}

Плоды калины богаты органическими кислотами, особенно валериановой кислотой. Из минеральных веществ ягоды содержат: марганец, цинк, железо, фосфор, медь, хром, йод, селен. Массовая доля железа в калине в 2-3 раза больше по сравнению с другими ягодами (рисунок 1).

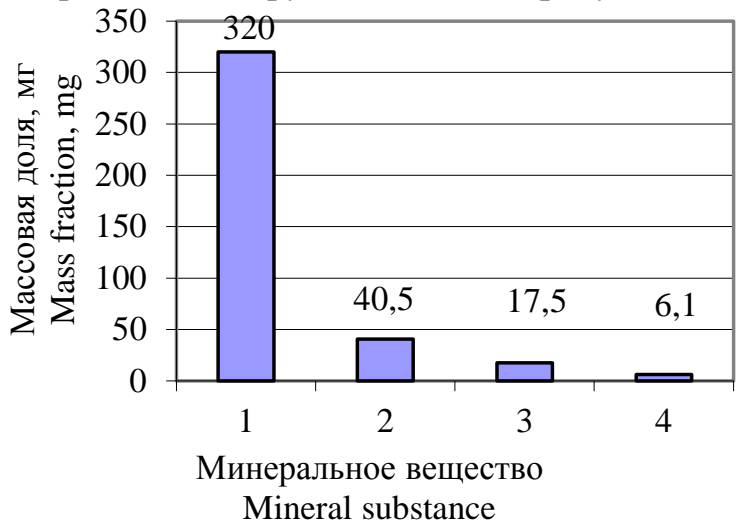

Рисунок 1. Массовая доля некоторых минеральных веществ в ягодах калины: 1 - калий, 2 - кальций, 3 - магний, 4 - железо

Figure 1. Minerals mass fraction in viburnum berries 1 - potassium, 2 - calcium, 3 - magnesium, 4 - iron
В калине на $70 \%$ больше витамина С, чем в лимоне, она также содержит витамины А, Е, Р и К (рисунок 2).

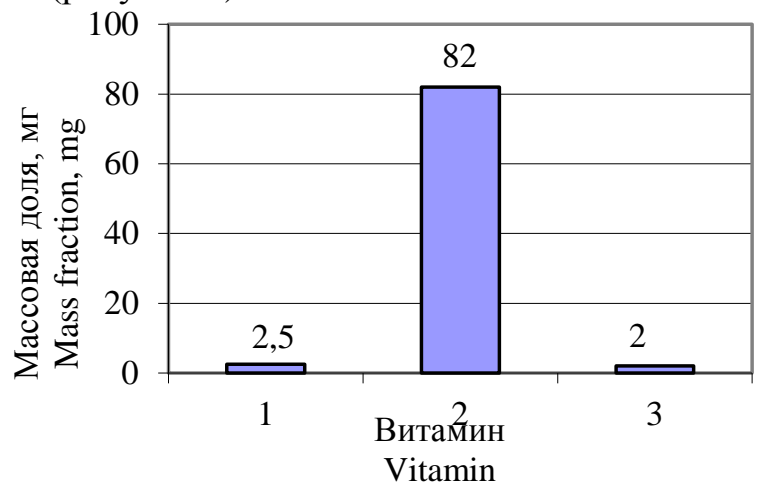

Рисунок 2. Массовая доля некоторых витаминов в ягодах калины: 1 - А, 2 - C, 3 - Е

Figure 2. Vitamins mass fraction in viburnum berries $1-\mathrm{A}, 2-\mathrm{C}, 3-\mathrm{E}$

Антиоксидантное действие токоферола заключается в способности защищать от окисления двойные связи в молекулах каротина и витамина А. Витамин Е является эффективным иммуномодулятором, способствующим укреплению иммунозащитных сил организма.

Витамин С является сильнейшим антиоксидантом, но он не способен накапливаться организмом человека, поэтому так важно его поступление с пищей.

Так как в используемом растительном сырье содержатся компоненты, обладающие антиоксидантным действием, представляет интерес исследование антиоксидантной активности сиропа калины. Последний определяли на приборе Цвет Яуза-01-АА. Получен результат 4,28 мг/дм³.

В ягодах присутствуют дубильные вещества, пектин, танин, кумарины, смолоподобные эфиры, гликозид вибурнин (очень полезен в составе калины, именно он делает ягоды горькими).

Известно использование сухого порошка калины в кефирных напитках, сметанных и творожных продуктах, причём горький вкус сырья воспринимается меньше в жирных и сладких продуктах.

Так как биологически активные вещества не разрушаются при замораживании и переработке, ягоды вымораживали и добавляли сахарозу. Сироп имел красивый рубиновый цвет и приятный вкус (горечь практически не ощутима).

На производстве используют два способа получения кисломолочных продуктов: резервуарный и термостатный [2].

Особенность резервуарного способа заключается в том, что сквашивание молока, созревание продукта и охлаждение ведутся в резервуарах большой вместимости и на розлив поступает готовый охлаждённый продукт. 
При термостатном способе заквашенное молоко сначала разливают в тару, дальнейший процесс сквашивания, созревание кисломолочного напитка, осуществляется в той же таре в термостатах, а затем в хладостатах.

Кисломолочный продукт вырабатывается резервуарным способом по следующей технологической схеме (рисунок 3.).

Технологический процесс получения кисломолочного продукта отличается от традиционного операциями подготовки компонентов и их внесением в готовый продукт. Особенностью рецептуры кисломолочного продукта является закваска, витаминный премикс и растительное сырье.

Использование лиофилизированной DVS культуры BB-12, состоящей из Bifidobacterium lactis в иммобилизованном виде, обогащает кисломолочный продукт смешанного брожения жизнеспособной пробиотической микрофлорой.

Заквасочная культура LAT LC K, состоящая из Lactococcus lactis subsp. lactis, Lactococcus lactis subsp. cremoris, Lactobacillus kefir, Acetobacter subsp. aceti, Saccharomyces lactis, позволяет получить кисломолочный продукт смешанного брожения с выраженными функциональными свойствами, высокой биологической эффективностью, пробиотическими свойствами и расширенным профилактическим действием.

Недостаток биологически активных веществ в молочных продуктах, может быть восполнен добавлением специальных компонентов [3-5].

Совместимость вносимых компонентов с кисломолочным продуктом определяли сенсорно по органолептическим показателям (таблица 1, 2).

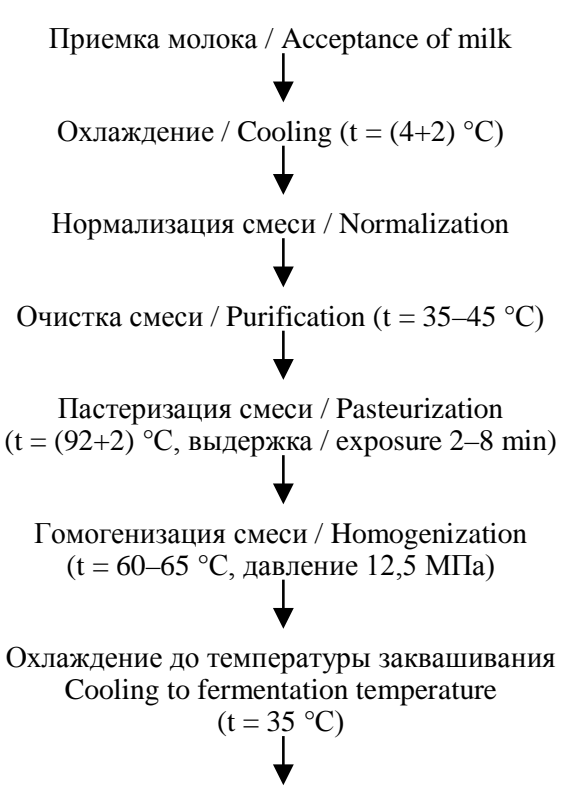

Заквашивание, внесение витаминного премикса и сиропа калины Fermentation, the introduction of vitamin premix and syrup of viburnum $\left(\mathrm{t}=35^{\circ} \mathrm{C}\right)$

Сквашивание / Fermentation

$\left(\mathrm{t}=35^{\circ} \mathrm{C}\right.$, кислотность / acidity 60-90 $\left.{ }^{\circ} \mathrm{T}\right)$

Охлаждение и созревание / Cooling and ripening ( $\mathrm{t}=18^{\circ} \mathrm{C}$, продолжительность / duration 5-10 h)

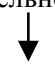

Фасование готового продукта / Wrapping of the finished product

Хранение готового продукта / Storage of the finished product $\left(\mathrm{t}=(4+2){ }^{\circ} \mathrm{C}\right)$

Рисунок 3. Технология получения кисломолочного продукта

Figure 3. Sour milk product technology

Таблица 1

Балльная шкала оценки качества кисломолочного продукта

Table 1

Grading scale assessment of sour milk product quality

\begin{tabular}{|c|c|c|}
\hline $\begin{array}{c}\text { Показатель } \\
\text { Factor }\end{array}$ & $\begin{array}{l}\text { Оценка, балл } \\
\text { Rating, point }\end{array}$ & $\begin{array}{c}\text { Характеристика } \\
\text { Characteristic }\end{array}$ \\
\hline \multirow{4}{*}{$\begin{array}{l}\text { Внешний вид } \\
\text { Appearance }\end{array}$} & 5 & Однородная, с нарушенным сгустком / Homogeneous, with impaired clot \\
\hline & 4 & Слегка неоднородная / Slightly inhomogeneous \\
\hline & 3 & Неоднородная / Heterogeneous \\
\hline & 2 & Значительное отделение сыворотки / Significant separation of serum \\
\hline \multirow{4}{*}{$\begin{array}{l}\text { Вкус } \\
\text { Taste }\end{array}$} & 5 & $\begin{array}{l}\text { Чистый кисломолочный, с привкусом вкусового компонента / } \\
\text { Clean fermented, with a flavor of the flavoring component }\end{array}$ \\
\hline & 4 & Хороший кисломолочный / Good dairy \\
\hline & 3 & Слабо выраженный / Weakly expressed \\
\hline & 2 & С посторонними привкусами / With foreign flavor \\
\hline \multirow{4}{*}{$\begin{array}{l}\text { Запах } \\
\text { Smell }\end{array}$} & 5 & $\begin{array}{l}\text { Ярко выраженный кисломолочный, с ароматом вкусового компонента / } \\
\text { Pronounced sour milk, with the aroma flavor component }\end{array}$ \\
\hline & 4 & Приятный, освежающий / A pleasant, refreshing \\
\hline & 3 & Слабовыраженный / Weakly pronounced odor \\
\hline & 2 & С посторонним запахом / With a foul smell \\
\hline \multirow{4}{*}{$\begin{array}{l}\text { Цвет } \\
\text { Colour }\end{array}$} & 5 & Равномерный / Uniform \\
\hline & 4 & Слегка не равномерный / Slightly not uniform \\
\hline & 3 & Неравномерный / Uneven \\
\hline & 2 & $\begin{array}{l}\text { С нехарактерным для данной группы продуктов цветом / } \\
\text { With uncharacteristic for this group of color products }\end{array}$ \\
\hline
\end{tabular}


Таблица 2

Органолептические показатели кисломолочного продукта

Table 2

Sour milk product organoleptic characteristics

\begin{tabular}{|c|c|}
\hline $\begin{array}{c}\text { Показатель } \\
\text { Factor }\end{array}$ & $\begin{array}{c}\text { Характеристика } \\
\text { Characteristic }\end{array}$ \\
\hline $\begin{array}{l}\text { Цвет } \\
\text { Colour }\end{array}$ & $\begin{array}{l}\text { Характерный для наполнителя, равно- } \\
\text { мерный по масce / Characteristic for the } \\
\text { filler, uniform mass }\end{array}$ \\
\hline $\begin{array}{l}\text { Вкус и запах } \\
\text { Taste and smell }\end{array}$ & $\begin{array}{l}\text { Кисломолочный, сладкий с ароматом и } \\
\text { вкусом калины / Fermented milk, sweet } \\
\text { with the scent and taste of raspberries }\end{array}$ \\
\hline $\begin{array}{l}\text { Консистенция } \\
\text { Consistency }\end{array}$ & $\begin{array}{l}\text { Однородная жидкость с нарушенным } \\
\text { сгустком / Homogeneous liquid with im- } \\
\text { paired clot }\end{array}$ \\
\hline
\end{tabular}

Найдены оптимальные дозировки вносимых компонентов (таблица 3). Введение в кисломолочный продукт витаминного премикса более 1,4 кг - экономически невыгодно, а если вносить менее 1,4 кг - продукт недостаточно обогащается витаминами. Использование сиропа калины более 100 кг на 1 т продукта приводит к потере индивидуального вкуса кисломолочного продукта, а если добавлять менее 100 кг, то теряется привкус наполнителя.

Установлено, что кисломолочный продукт богат витаминами и минеральными веществами. Потребление 100 г. кисломолочного

\section{ЛИТЕРАТУРА}

1 Korzhov R.P., Ponomarev A.N., Melnikova E.I., Bogdanova E.V. Preclinical studies of kefir product with reduced allergenicity of b-lactoglobulin // Foods and Raw Materials. 2015. T. 3. № 2. C. 115-121.

2 Твердохлеб Г.В., Сажинов Г.Ю., Раманаускас Р.И. Технология молока и молочных продуктов: учеб. пособие. М.: ДеЛи принт, 2006. 616 с.

3 Dolmatova O.I. Outline keeping of milk product. // Materiály X mezinárodní vědecko praktická konference «Věda a technologie: krok do budoucnosti - 2014». Praha: Education and Science, 2014. P. 41-43.

4 Пономарев А.Н., Мельникова Е.И., Богданова Е.В., Болгова Е.В. Синбиотический напиток с экстрактом скорцонеры // Пищевая промышленность. 2013. № 12. С. 72-73.

5 Голубева Л.В., Долматова О.И., Бандура В.Ф. Изучение свойств творожного продукта с компонентами растительного происхождения // Вестник Воронежского государственного университета инженерных технологий. 2015. № 2 (64). С. 108 -111. продукта с витаминным премиксом, удовлетворяет суточную потребность в витаминах $\mathrm{A}$, группы B, C, D, E на 40-50\%.

Таблица 3

Рецептура кисломолочного продукта на 1 т (без учёта потерь)

Table 3. Sour milk product per 1 ton recipe (excluding losses)

\begin{tabular}{|l|c|}
\hline \multicolumn{1}{|c|}{$\begin{array}{c}\text { Наименование компонента } \\
\text { Сотропеnt }\end{array}$} & $\begin{array}{c}\text { Macca, кг } \\
\text { Mass, kg }\end{array}$ \\
\hline $\begin{array}{l}\text { Молоко цельное } \\
\text { whole milk }\end{array}$ & 650 \\
\hline $\begin{array}{l}\text { Молоко обезжиренное } \\
\text { Skim milk }\end{array}$ & 248,5 \\
\hline $\begin{array}{l}\text { Закваска (прямого внесения) } \\
\text { Sour (direct inoculation) }\end{array}$ & 0,1 \\
\hline $\begin{array}{l}\text { Витаминный премикс } \\
\text { Vitamin рremix }\end{array}$ & 1,4 \\
\hline $\begin{array}{l}\text { Сироп калины } \\
\text { Sугuр of viburnum }\end{array}$ & 100 \\
\hline
\end{tabular}

Заключение

По результатам исследований разработана рецептура кисломолочного продукта, проведена оценка качества. Производство кисломолочного продукта позволяет расширить ассортимент молочной продукции функциональной направленности.

\section{REFERENCES}

1 Korzhov R.P., Ponomarev A.N., Melnikova E.I., Bogdanova E.V. Preclinical studies of kefir product with reduced allergenicity of b-lactoglobulin. Foods and Raw Materials, 2015, vol. 3, no. 2, pp. 115-121.

2 Tverdokhleb G.V., Sazhinov G.Yu., Ramanauskas R.I. Tekhnologiya moloka i molochnykh produktov [Technology of milk and dairy products] Moscow, DeLee print, 2006. 616 p. (in Russian).

3 Dolmatova O.I. Outline keeping of milk product. Materials X international scientific-practical conference "Science and technology: a step into the future - 2014». Prague, 2014. pp. 41-43.

4 Ponomarev A.N, Melnikova E.I, Bogdanova E.V, Bolgova E.V. Synbiotic drink with extract of scorzonera. Pishchevaya promyshlennost' [Food Industry] 2013, no. 12, pp. 72-73. (in Russian)

5 Golubeva L.V, Dolmatova O.I, Bandura V.F. Studying the properties of quark products with ingredients of plant origin. Vestnik VGUIT [Proceedings of VSUET] 2015, no. 2 (64), pp. 108 -111. (in Russian). 


\section{СВЕДЕНИЯ ОБ АВТОРАХ}

Любовь В. Голубева д.т.н., профессор, кафедра технологии продуктов животного происхождения, Воронежский государственный университет инженерных технологий, пр. Революции, 19, г. Воронеж, Россия, lvgolubeva@inbox.ru Ольга И. Долматова к.т.н., доцент, кафедра технологии продуктов животного происхождения, Воронежский государственный университет инженерных технологий, пр. Революции, 19, г. Воронеж, Россия, Olgadolmatova@rambler.ru Марина И. Иванцова студент, кафедра технологии продуктов животного происхождения, Воронежский государственный университет инженерных технологий, пр. Революции, 19, г. Воронеж, Россия

\section{КРИТЕРИЙ АВТОРСТВА}

Любовь В. Голубева консультация в ходе исследования, корректировала рукопись до подачи в редакцию

Ольга И. Долматова консультация в ходе исследования, написала рукопись, несёт ответственность за плагиат

Марина И. Иванцова обзор литературных источников по исследуемой проблеме, провела эксперимент, выполнила расчёты

\section{КОНФЛИКТ ИНТЕРЕСОВ}

Авторы заявляют об отсутствии конфликта интересов.

ПОСТУПИЛА 06.04.2016

ПРИНЯТА В ПЕЧАТЬ 04.05.2016

\section{INFORMATION ABOUT AUTHORS}

Lyubov V. Golubeva Doc. Sci., professor, department of technology products of animal origin, Voronezh state university of engineering technology, Revolution Av., 19, Voronezh, Russia, lvgolubeva@inbox.ru

Olga I. Dolmatova $\mathrm{PhD}$, associate professor, department of technology products of animal origin, Voronezh state university of engineering technology, Revolution Av., 19, Voronezh, Russia Olgadolmatova@rambler.ru

Marina I. Ivantsova student, department of technology products of animal origin, Voronezh state university of engineering technology, Revolution Av., 19, Voronezh, Russia

\section{CONTRIBUTION}

Lyubov V. Golubeva consultation during the study adjusted the manuscript prior to submission to the Editor

Olga I. Dolmatova consultation during the study and wrote the manuscript, is responsible for plagiarism

Marina I. Ivantsova review of the literature on the researched topic, conducted an experiment, performed calculations

\section{CONFLICT OF INTEREST}

The authors declare no conflict of interest.

RECEIVED 4.6.2016

ACCEPTED 5.4.2016 